\title{
Infrared Hole Burning of the Amino Group in Amino Acid and Peptide Salts
}

\author{
Hung-Wen $\mathrm{Li}^{\dagger}$ and Herbert L. Strauss* \\ Department of Chemistry, University of California, Berkeley, California 94720-1460
}

Received: October 12, 2000; In Final Form: December 28, 2000

\begin{abstract}
Monodeuterated derivatives of the salts of tyrosine, valine, glycylglycine, and glycylglycylglycine are investigated by infrared spectroscopy. Irradiation in the spectral region of the $\mathrm{N}-\mathrm{D}$ stretch bands produces spectral holes and antiholes. These result from rotation of $\mathrm{N}-\mathrm{D}$-containing moieties. The holes and antiholes identify the vibrations of the amino group and provide information on the hydrogen-bonding environment. Both the various amino acid salts and the two peptide salts hole burn, suggesting that infrared hole burning will provide a useful tool for investigating a range of biologically interesting materials.
\end{abstract}

\section{Introduction}

In previous work, we have shown that glycine and alanine hydrochlorides doped with some deuterium can be hole-burned. ${ }^{1}$ The deuterium forms a small amount of $\mathrm{NH}_{2} \mathrm{D}^{+}$in the amino acid salt $\mathrm{RCH}(\mathrm{COOH}) \mathrm{NH}_{3}{ }^{+} \mathrm{Cl}^{-}$. Irradiating the $\mathrm{N}-\mathrm{D}$ stretch bands with a laser forms spectral holes and antiholes. We interpret the results of the irradiation by analogy with our extensive series of studies on ammonium salts doped with deuterium. ${ }^{2}$ The ammonium ions rotate on irradiation and, in the absence of the radiation, tunnel back to their original orientational distribution.

Although the major vibrational bands of the amino acids and polypeptides below about $2000 \mathrm{~cm}^{-1}$ have long been wellcharacterized, ${ }^{3-5}$ this is not true of those above $2000 \mathrm{~cm}^{-1}$. Indeed, this spectral region contains "almost continuous bands", which are rather weak. ${ }^{3}$ A particular difficulty is that the $\mathrm{N}-\mathrm{H}$ vibrations change a great deal on changing the hydrogen bonding (for example, on changing the solvent). Both the $\mathrm{N}-\mathrm{H}$ and $\mathrm{N}-\mathrm{D}$ vibrations turn out to be mixed with a variety of other vibrations, such as the bends of the $\mathrm{NH}_{2} \mathrm{D}^{+}$, and all of these change with a change in the position of the $\mathrm{N}-\mathrm{H}(\mathrm{N}-\mathrm{D})$. Careful comparison of the spectra of $\left[\mathrm{N}^{14}\right]$ glycine and $\left[\mathrm{N}^{15}\right]$ glycine (each containing a small amount of deuterium) and the corresponding holes/ antiholes identified the bands sensitive to orientation of the $\mathrm{NH}_{2} \mathrm{D}^{+}$group. ${ }^{6}$ Only discrete positions in the $\mathrm{N}-\mathrm{D}$ stretching region of the spectrum were irradiated, but holes and antiholes appear both there $\left(2100-2400 \mathrm{~cm}^{-1}\right)$ and in the mid-infrared $\left(1600-800 \mathrm{~cm}^{-1}\right)$. Each mid-infrared hole can be identified with a band belonging to the conformation of the $\mathrm{NH}_{2} \mathrm{D}^{+}$group whose population is diminished by the irradiation of its $\mathrm{N}-\mathrm{D}$ stretch band.

Having found hole burning in glycine and alanine, we now try a number of other amino acids and simple polypeptides to assess the potential of infrared hole burning for characterizing amino groups and their hydrogen bonding in general. We present the experimental results for these compounds here. We start with two amino acid salts whose crystal structures are known, tyrosine and valine hydrochlorides, and then briefly consider the peptide salts Gly-Gly and Gly-Gly-Gly hydrochlorides.

\footnotetext{
† Present address: Department of Biochemistry, MS 009, Brandeis University, Waltham, MA 02454.

* Corresponding author.
}

\section{Experimental Section}

The amino acid samples L-tyrosine (60-18-4) $\left(\mathrm{R}=\mathrm{CH}_{2} \mathrm{C}_{6} \mathrm{H}_{4}\right.$ $\mathrm{OH})$ and L-valine (72-18-4) $\left(\mathrm{R}=\mathrm{CH}\left(\mathrm{CH}_{3}\right)_{2}\right)$ are from Aldrich with a nominal purity of $99 \%$. The polypeptide Gly-Gly (55650-3) is from Aldrich and Gly-Gly-Gly (556-33-2) is from Sigma. The salts are prepared by dissolving the amino acids in slightly warm concentrated hydrochloric acid containing about $5 \% \mathrm{D}_{2} \mathrm{O}$. The salts crystallize on cooling the solution to room temperature, and the resulting transparent needlelike crystals are then mulled in mineral oil. The mull is put between $\mathrm{CaF}_{2}$ windows and mounted in a cryostat, as in our previous experiments. ${ }^{1,6}$ The Gly-Gly-Gly salt proved to be more difficult to crystallize than the other salts. Most of the spectra were taken with an InSb detector in the spectral range 2000-4000 $\mathrm{cm}^{-1}$ with 128 scans accumulated in 5 min.

Interpretation of the spectra requires that there be at most one deuterium per amino group. This was checked by taking spectra of samples containing different amounts of deuterium and making sure that the spectra we consider further are in the low deuterium concentration limit. We have previously checked that the complex spectral features we observe for glycine hydrochloride are not due to the half-salt, diglycine hydrochloride. ${ }^{6}$

Long irradiation times of up to $1 \mathrm{~h}$ with a differencefrequency laser ${ }^{6}$ at about $80 \mathrm{~mW} / \mathrm{cm}^{2}$ were used. ${ }^{7}$ Atmospheric $\mathrm{CO}_{2}$ was not effectively purged from the difference-frequency laser path, and this markedly reduced the power available from 2390 to $2290 \mathrm{~cm}^{-1}$. We therefore also used a diode laser, which delivered more power in this spectral region. We estimate that the bandwidth of the difference frequency laser is about $1 \mathrm{~cm}^{-1}$. The width of the diode laser is much less than this (perhaps $10^{-3} \mathrm{~cm}^{-1}$ ) for each mode, but the laser was run multiple mode and unstabilized, and the resulting averaged bandwidth is also about $1 \mathrm{~cm}^{-1}$. The observed hole widths were about $8 \mathrm{~cm}^{-1}$ for the difference-frequency laser and about $5 \mathrm{~cm}^{-1}$ for the diode laser-we do not interpret this difference in widths, since the diode laser power has an unknown frequency distribution (that is, it may not be Gaussian). Also effective for hole-burning was overnight irradiation using the Nernst Glower spectrometer as a broadband source.

\section{Results}

Tyrosine Hydrochloride. Tyrosine hydrochloride crystallizes in the monoclinic space group, $P 2_{1}$ (No. 4), with 2 molecules 


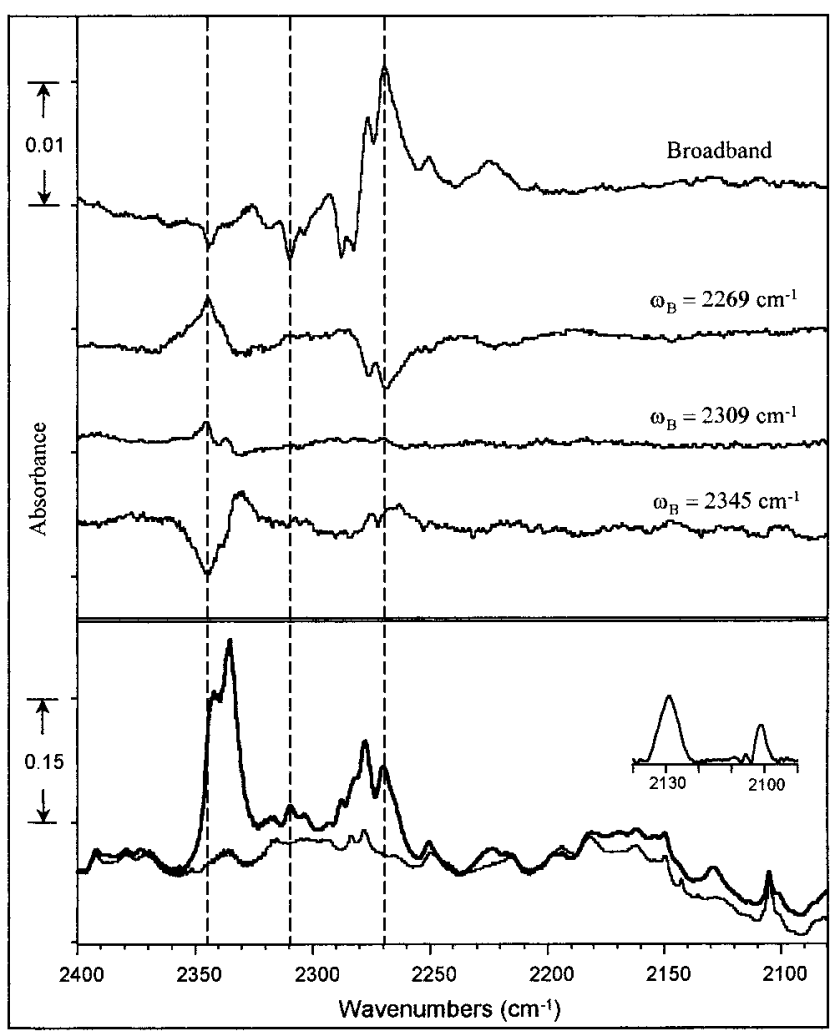

Figure 1. The infrared hole burning spectra of tyrosine hydrochloride at $10 \mathrm{~K}$ doped with about $4 \%$ deuterium. The absorption spectra of the deuterated tyrosine hydrochloride (heavy line) and the undeuterated species (light line) are shown in the bottom panel. The dashed vertical lines are at 2269, 2309, and $2345 \mathrm{~cm}^{-1}$. The sample was irradiated by the difference frequency laser for an hour. The inset in the bottom panel is the difference of the heavy and the light curve between 2140 to 2090 $\mathrm{cm}^{-1}$; the 2128 and $2101 \mathrm{~cm}^{-1}$ bands are deuterium-related.

per unit cell as shown by neutron diffraction. ${ }^{8}$ The amino group is a general position ( $C_{1}$ symmetry), which gives three different $\mathrm{N}-\mathrm{D}$ conformations. In addition, the carboxyl acid $\mathrm{OH}(\mathrm{OD})$ and the phenyl $\mathrm{OH}(\mathrm{OD})$ can each give rise to a stretch band in the same spectral region. The absorption spectrum of the partially deuterated tyrosine hydrochloride $(\sim 5 \% \mathrm{D})$ is shown by the heavy curve in the bottom panel of Figure 1; the undeuterated spectrum is shown by the light curve. The difference between these two curves is due to deuterium-related bands ( $\mathrm{N}-\mathrm{D}$ and $\mathrm{O}-\mathrm{D}$ bands). As for the glycine and alanine salts, there are more such bands than expected, and this is evidence for the presence of Fermi resonances and other vibrational combinations. ${ }^{1}$ The infrared hole burning results are shown in the upper panels, with the laser frequency $\left(\omega_{\mathrm{B}}\right)$ specified for each spectrum.

The infrared broadband excitation of the tyrosine salt results in holes at 2345, 2309, 2288, and $2282 \mathrm{~cm}^{-1}$ and antiholes at $2276,2269,2250$, and around $2225 \mathrm{~cm}^{-1}$, with no other obvious spectral change. These are the positions of possible $\mathrm{N}-\mathrm{D}$ stretching bands. Irradiating with the laser set to these positions, we observed three different hole/antihole patterns, shown in Figure 1 and summarized in Table 1. In this table, a downward arrow designates a hole, while an upward one designates an antihole. For example, when setting the irradiating laser to 2269 $\mathrm{cm}^{-1}$, we observe holes at 2269 and $2276 \mathrm{~cm}^{-1}$, antiholes at $2282,2288,2309$, and $2345 \mathrm{~cm}^{-1}$, and no obvious change in the $2333 \mathrm{~cm}^{-1}$ band. Laser irradiation at the 2276 and 2333 $\mathrm{cm}^{-1}$ bands produces shallower holes but the same hole/antihole pattern as that for irradiation at $2269 \mathrm{~cm}^{-1}$. Thus the bands at 2276 and $2333 \mathrm{~cm}^{-1}$ belong to the same conformation as the
TABLE 1: Summary of Hole Burning Results of Tyrosine Hydrochloride $^{a}$

\begin{tabular}{lccccccc}
\hline \multirow{2}{*}{$\begin{array}{c}\text { irradiation freq } \\
\left(\mathrm{cm}^{-1}\right)\end{array}$} & 2345 & 2288 & 2282 & 2333 & 2276 & 2269 & 2309 \\
\cline { 2 - 7 } broadband & $\downarrow$ & $\downarrow$ & $\downarrow$ & & $\uparrow$ & $\uparrow$ & $\downarrow$ \\
2345 & $\downarrow$ & $\downarrow$ & $\downarrow$ & $\uparrow$ & $\uparrow$ & $\uparrow$ & \\
2288 & $\downarrow$ & $\downarrow$ & $\downarrow$ & $\uparrow$ & $\uparrow$ & $\uparrow$ & $\downarrow$ \\
2282 & $\downarrow$ & $\downarrow$ & $\downarrow$ & $\uparrow$ & $\uparrow$ & $\uparrow$ & $\downarrow$ \\
2333 & $\uparrow$ & & & $\downarrow$ & & & \\
2276 & $\uparrow$ & $\uparrow$ & $\uparrow$ & & $\downarrow$ & $\downarrow$ & \\
2269 & $\uparrow$ & $\uparrow$ & $\uparrow$ & & $\downarrow$ & $\downarrow$ & $\uparrow$ \\
2309 & $\uparrow$ & & & & & $\uparrow$ & $(?)$
\end{tabular}
hole.

${ }^{a} \mathrm{Up}$ arrow $(\uparrow)$ indicates an anti-hole and down arrow $(\downarrow)$ indicates a

TABLE 2: Hydrogen Bond Parameters for Tyrosine Hycrochloride $^{a}$

\begin{tabular}{lccccc}
\hline \multicolumn{1}{c}{$\mathrm{A}-\mathrm{H} \cdots \mathrm{B}$} & $\mathrm{A} \cdots \mathrm{B}(\AA)$ & $\mathrm{A}-\mathrm{H}$ & $\mathrm{H} \cdots \mathrm{B}$ & $\begin{array}{c}<\mathrm{A}-\mathrm{H} \cdots \mathrm{B} \\
(\mathrm{deg})\end{array}$ & $\begin{array}{c}\mathrm{A}-\mathrm{D} \operatorname{stretch}^{b} \\
\left(\mathrm{~cm}^{-1}\right)\end{array}$ \\
\hline $\mathrm{N}-\mathrm{H}^{1} \cdots \mathrm{Cl}$ & $3.251(3)$ & 1.007 & $2.378(5)$ & $144.5(3)$ & $2269(2276$, \\
& & & & & $2333)$ \\
$\mathrm{N}-\mathrm{H}^{2} \cdots \mathrm{Cl}$ & $3.452(3)$ & 1.017 & $2.471(7)$ & $161.8(4)$ & $2345(2288$, \\
& & & & & $2282)$ \\
$\mathrm{N}-\mathrm{H}^{2} \cdots \mathrm{O}^{1}-\mathrm{C}$ & $2.901(5)$ & & $2.420(5)^{\mathrm{c}}$ & $108.0(4)^{\mathrm{c}}$ & \\
$\mathrm{N}-\mathrm{H}^{3} \cdots \mathrm{Cl}$ & $3.329(3)$ & 1.020 & $2.505(8)$ & $137.4(4)$ & 2309 \\
$\mathrm{O}^{\eta}-\mathrm{H}^{\eta \cdots} \cdot \mathrm{Cl}$ & $3.045(3)$ & 0.988 & $2.078(5)$ & $165.6(3)$ & $2128,2101 ?$ \\
$\mathrm{O}^{2}-\mathrm{H}^{02 \cdots} \mathrm{O}^{\eta}-\mathrm{C}^{\zeta}$ & $2.619(4)$ & 1.018 & $1.609(5)$ & $170.7(4)$ & $2340 ?$
\end{tabular}

${ }^{a}$ Neutron diffraction data. ${ }^{8}$ The numbering here follows the diffraction paper, where $\mathrm{O}^{\eta}$ is the phenol oxygen and $\mathrm{C}^{\xi}$ is the carbon in the benzene ring connecting to the O. ${ }^{b}$ This work. ${ }^{c}$ Probably not a hydrogen bond, see ref 8 .

$2269 \mathrm{~cm}^{-1}$ band. The same reasoning says that the bands at 2282 and $2288 \mathrm{~cm}^{-1}$ belong to the conformation of the 2345 $\mathrm{cm}^{-1}$ band. On the other hand, irradiation of the deuteriumrelated band at $2340 \mathrm{~cm}^{-1}$ does not produce any obvious spectral changes. We conclude that the major bands corresponding to three different $\mathrm{N}-\mathrm{D}$ conformations are at 2269, 2309, and 2345 $\mathrm{cm}^{-1}$. In Table 2, we correlate these hydrogen-bonded N-D stretching frequencies with the hydrogen-bonding structural parameters. We compare with other amino acid salts below, but here we note that the heavy atom distances of the amino group in tyrosine hydrochloride are relatively long, producing weak hydrogen bonds and high $\mathrm{N}-\mathrm{D}$ stretching frequencies. Two deuterium-related bands at low frequency, 2101 and 2128 $\mathrm{cm}^{-1}$, did not burn at all, either with laser or broadband irradiation. They are near the frequencies assigned to $\mathrm{O}-\mathrm{D}$ stretches in other compounds and are assigned as such here. ${ }^{6}$ The large red shift of these $\mathrm{O}-\mathrm{D}$ stretching bands is caused by strong hydrogen bonds with the oxygen atom electron donor. The band at $2340 \mathrm{~cm}^{-1}$ remains to be assigned. It must be a combination or overtone of one of the deuterium motions (either $\mathrm{N}-\mathrm{D}$ or $\mathrm{O}-\mathrm{D}$ ), or if it is an $\mathrm{O}-\mathrm{D}$ stretch, it corresponds to a weak hydrogen bond. Then the two bands at 2128 and 2101 $\mathrm{cm}^{-1}$ are simply two components of the other hydrogen bond (see Table 2).

Valine Hydrochloride. Valine hydrochloride crystallizes in the same monoclinic space group, $P 2_{1}$, as the tyrosine salt, and the amino group sits in a site of $C_{1}$ symmetry. ${ }^{9}$ The absorption spectra of valine hydrochloride are shown in Figure 2. Only bands in the region from 2200 to $2280 \mathrm{~cm}^{-1}$ change upon infrared irradiation. Instead of distinct holes and antiholes, the broadband excitation of valine hydrochloride shows a broad antihole centered at $2245 \mathrm{~cm}^{-1}$ and some spectral features at 2200 and $2270 \mathrm{~cm}^{-1}$. Since the broadband glower radiation can be absorbed by many of the vibrational bands, the net change is the result of different absorption and different relaxation rates 


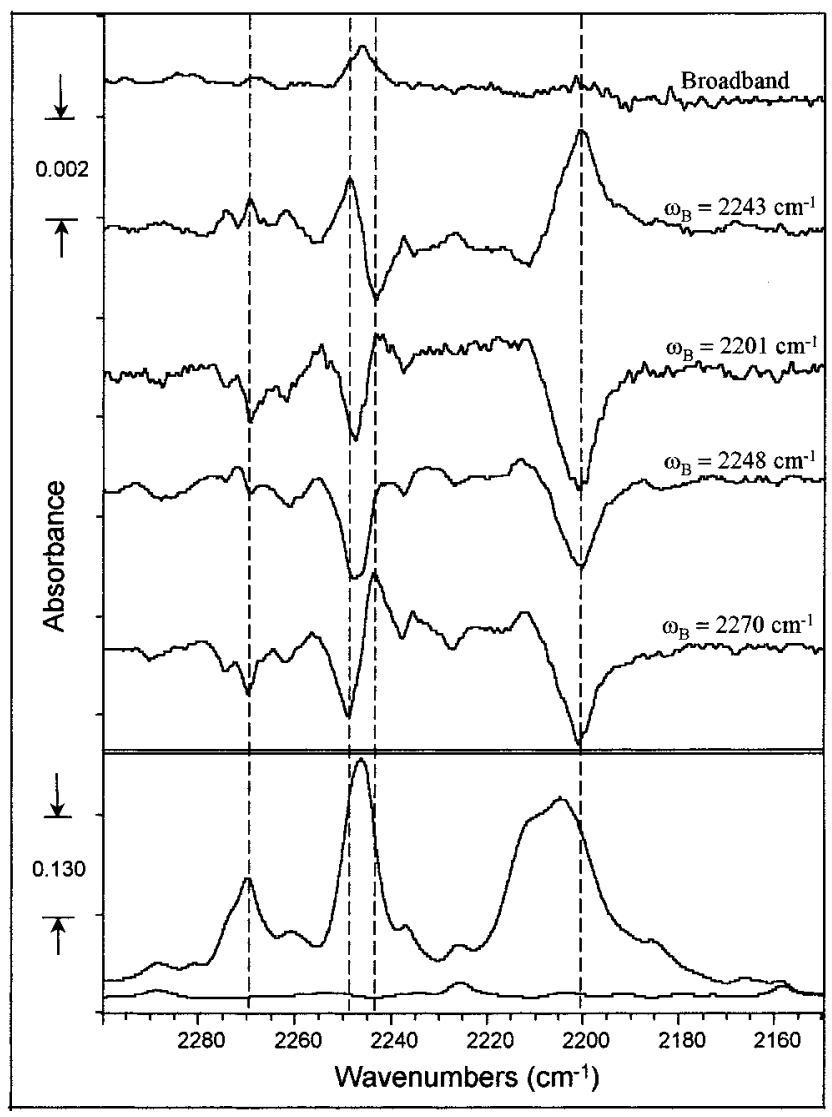

Figure 2. The same as Figure 1, but for valine hydrochloride and for thirty minutes laser irradiation. The dashed vertical lines are at 2201 , 2243,2248 , and $2270 \mathrm{~cm}^{-1}$.

TABLE 3: Summary fo Hole Burning Results of Valine Hydrochloride $^{a}$

\begin{tabular}{clccc}
\hline & \multicolumn{4}{c}{ peak position } \\
\cline { 2 - 5 } irradiation freq $\left(\mathrm{cm}^{-1}\right)$ & 2270 & 2248 & 2201 & 2243 \\
\hline broadband & $(?)$ & $\uparrow$ & $(?)$ & $\uparrow$ \\
2270 & $\downarrow$ & $\downarrow$ & $\downarrow$ & $\uparrow$ \\
2248 & $\downarrow(?)$ & $\downarrow$ & $\downarrow$ & $(?)$ \\
2201 & $\downarrow$ & $\downarrow$ & $\downarrow$ & $(?)$ \\
2243 & $\uparrow$ & $\uparrow$ & $\uparrow$ & $\downarrow$
\end{tabular}
hole.

at the different spectral positions. If highly overlapped vibrational bands have similar relaxation rates, the overlapped holes and antiholes can lead to small, broad features such as those observed here.

Again, we explore the possible N-D stretching bands by looking at the difference between the absorption spectra of the deuterated and the nondeuterated molecules (Figure 2) and then irradiating at specific frequencies. The holes and antiholes show up when the laser is set at 2201, 2243, 2248, and $2270 \mathrm{~cm}^{-1}$. The hole-burning spectra shown in Figure 2 indicate that the behavior of the $2243 \mathrm{~cm}^{-1}$ band is distinctly different from that of the other bands and clearly assigns the $2243 \mathrm{~cm}^{-1}$ mode to one of the $\mathrm{N}-\mathrm{D}$ conformations. When the laser frequency is set at $2270 \mathrm{~cm}^{-1}$, we observe holes at 2248 and $2201 \mathrm{~cm}^{-1}$ and an antihole at $2243 \mathrm{~cm}^{-1}$. However, when the laser frequency is set at 2248 or $2201 \mathrm{~cm}^{-1}$, similar hole-burning patterns with no obvious antiholes result, as summarized in Table 3 . We conclude that the $2270 \mathrm{~cm}^{-1}$ band belongs to the second N-D conformation. The 2248 and $2201 \mathrm{~cm}^{-1}$ bands both belong to the third conformation, which produces two clear
TABLE 4: Hydrogen Bonding Parameters for Valine Hydrochloride $^{a}$

\begin{tabular}{cccccc}
\hline $\mathrm{A}-\mathrm{H} \cdots \mathrm{B}$ & $\mathrm{A} \cdots \mathrm{B}(\AA)$ & $\mathrm{A}-\mathrm{H}$ & $\mathrm{H} \cdots \mathrm{B}$ & $\begin{array}{c}<\mathrm{A}-\mathrm{H} \cdots \mathrm{B} \\
(\mathrm{deg})\end{array}$ & $\begin{array}{c}\mathrm{A}-\mathrm{D} \mathrm{stretch}^{b} \\
\left(\mathrm{~cm}^{-1}\right)\end{array}$ \\
\hline $\mathrm{N}-\mathrm{H}^{1} \cdots \mathrm{Cl}$ & $3.374(2)$ & 1.030 & $2.356(4)$ & $169.4(3)$ & 2270 \\
$\mathrm{~N}-\mathrm{H}^{3} \cdots \mathrm{Cl}$ & $3.224(2)$ & 1.041 & $2.263(4)$ & $154.5(3)$ & 2248,2201 \\
$\mathrm{~N}-\mathrm{H}^{2} \cdots \mathrm{Cl}$ & $3.187(1)$ & 1.031 & $2.161(4)$ & $168.1(4)$ & 2243 \\
$\mathrm{O}-\mathrm{H}^{1} \cdots \mathrm{Cl}$ & $2.986(2)$ & 1.007 & $1.990(3)$ & $169.4(4)$ & 2184
\end{tabular}

${ }^{a}$ Neutron diffraction data. ${ }^{9}{ }^{b}$ This work.

TABLE 5: Correlation of N-D Stretching Frequency and Hydrogen Bonding Parameters

\begin{tabular}{|c|c|c|c|}
\hline point & $\begin{array}{c}v_{\mathrm{N}-\mathrm{D}} \\
\left(\mathrm{cm}^{-1}\right)\end{array}$ & $\begin{array}{c}r_{\mathrm{H} \cdots \mathrm{Cl}} \\
(\AA)\end{array}$ & $\begin{array}{c}\angle \mathrm{N}-\mathrm{H} \cdots \mathrm{Cl} \\
(\mathrm{deg})\end{array}$ \\
\hline \multicolumn{4}{|c|}{ Glycine Hydrochloride } \\
\hline 1 & $2238^{\circ}$ & 2.160 & 170.8 \\
\hline 2 & 2187 & 2.123 & 166.4 \\
\hline 3 & 2368 & 2.593 & 126.7 \\
\hline \multicolumn{4}{|c|}{ Alanine Hydrochloride } \\
\hline 4 & 2229 & 2.21 & 162 \\
\hline 5 & 2201 & 2.11 & 162 \\
\hline 6 & 2362 & 2.73 & 114 \\
\hline \multicolumn{4}{|c|}{ Tyrosine Hydrochloride } \\
\hline 7 & 2269 & 2.378 & 144.5 \\
\hline 8 & 2345 & 2.471 & 161.8 \\
\hline 9 & 2309 & 2.505 & 137.4 \\
\hline \multicolumn{4}{|c|}{ Valine Hydrochloride } \\
\hline 10 & 2270 & 2.356 & 169.4 \\
\hline 11 & 2243 & 2.161 & 168.1 \\
\hline 12 & 2248 & 2.263 & 154.5 \\
\hline \multicolumn{4}{|c|}{ Literature Values $^{a}$} \\
\hline 13 & 2371 & 2.45 & 130 \\
\hline 14 & 2372 & 2.46 & 130 \\
\hline 15 & 2374 & 2.52 & 131 \\
\hline 16 & 2367 & 2.56 & 132 \\
\hline 17 & 2359 & 2.58 & 132 \\
\hline
\end{tabular}

${ }^{a}$ The literature values are for the hydrogen bonds in the ammonium salts of hexachlorometal anions. ${ }^{12}$

bands due to Fermi resonance. We correlate the N-D stretching frequencies with the hydrogen-bond parameters of Table 4.

The broad absorption peak centered at $2245 \mathrm{~cm}^{-1}$, shown at the bottom of Figure 2, is actually the superposition of the 2243 and $2248 \mathrm{~cm}^{-1}$ modes. These two modes belong to two different $\mathrm{N}-\mathrm{D}$ conformations, and their irradiation results in opposite hole/antihole patterns. These two different hole-burning patterns tend to cancel and lead to the small, broad feature resulting from the broadband irradiation.

\section{Discussion}

It has long been known that the $\mathrm{A}-\mathrm{H}$ (or D) stretching frequency of a hydrogen bond, where $\mathrm{A}$ is the donor atom, correlates with the energy of the band and many other properties. ${ }^{10,11}$

We have studied the simple hydrogen-bonded amino acid hydrochloride salts glycine, alanine, tyrosine, and valine. The most complete literature correlations are for $\mathrm{O}-\mathrm{H}-\mathrm{O}$ hydrogen bonds, but other hydrogen bonds such as $\mathrm{N}-\mathrm{H}-\mathrm{Cl}$ bonds have also been considered from the beginning. The correlation of hydrogen-bonding distances and angles with $\mathrm{N}-\mathrm{D}$ stretching frequencies of four amino acid hydrochloride salts is summarized in Table 5 and Figure 3. The three-dimensional graph in Figure 3 is for the $\mathrm{N}-\mathrm{D}-\mathrm{Cl}$ bonds in the amino acids. The correlation among the bond distances, angles, and the stretching frequencies runs in an approximately diagonal line from a straight short bond at low frequency to a bent, long bond at 


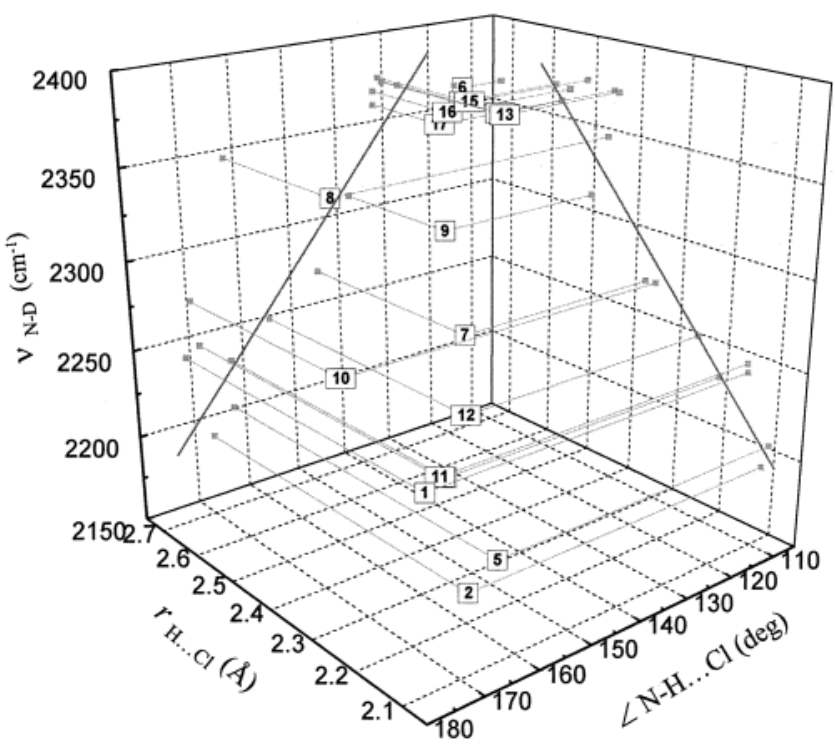

Figure 3. Correlation among $\mathrm{N}-\mathrm{D}$ stretching frequencies, hydrogen bond distances, $\mathrm{H} \cdots \mathrm{Cl}$, and hydrogen bond angles, $\mathrm{N}-\mathrm{H} \cdots \mathrm{Cl}$, for the $\mathrm{N}-\mathrm{H} \cdots \mathrm{Cl}$ type of hydrogen bonding in four simple amino acid hydrochloride salts. Points $1-3$ are for glycine, $4-6$ are for alanine, 7-9 are for tyrosine, 10-12 are for valine, and 13-17 are literature values for the same type of hydrogen bond. See text for detail.

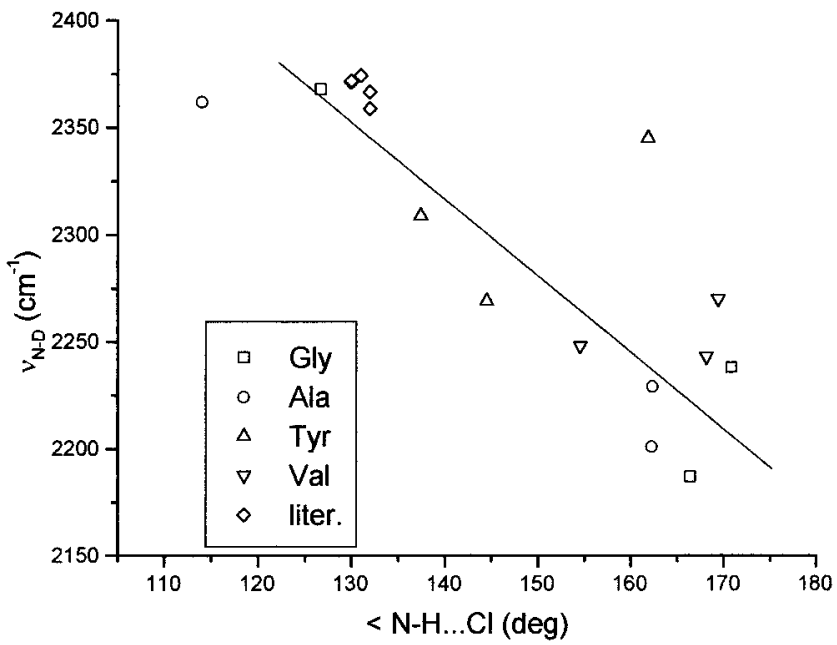

Figure 4. The projection of Figure 3 on the plane of frequency with hydrogen bond angle. The data show a linear relationship with a correlation coefficient, $R=-0.93$. Some of the data scatter is due to bifurcated hydrogen bonds. The standard deviation is $47.4 \mathrm{~cm}^{-1}$.

high frequency. Data points $13-17$ are literature values from the study by Knop et al. ${ }^{12}$ on the $\mathrm{NH}_{3} \mathrm{D}^{+}$ion in cubic $\left(\mathrm{NH}_{4}\right)_{2}$ $\mathrm{MCl}_{6}$ crystals at $77 \mathrm{~K}$. Data point 8 diverges from the trend, but it is for a bifurcated hydrogen bond. The projections of the data on the frequency vs the $\mathrm{H}-\mathrm{Cl}$ distance and frequency vs bond angle planes are shown in Figure 3 and plotted separately in Figures 4 and 5. Both projections show good correlation and, of course, also imply a correlation between the $\mathrm{H}-\mathrm{Cl}$ distance and the angle. Further interpretation of the data is confounded by the errors inherent in the X-ray data and the discrepancies between the X-ray and neutron data. A short summary of these problems is provided by Jeffrey. ${ }^{10} \mathrm{We}$ tried to correlate the frequencies with the $\mathrm{N}-\mathrm{Cl}$ and $\mathrm{N}-\mathrm{H}$ distances but with no success. There are also $\mathrm{O}-\mathrm{H} \cdots \mathrm{Cl}($ or $\mathrm{O}-\mathrm{D} \cdots \mathrm{Cl}$ ) bands in our spectra, but we do not have enough data to define a good correlation.

It is possible to fit the deuterium-related features in the spectra as sums of Lorentzian peaks and thus determine their widths.

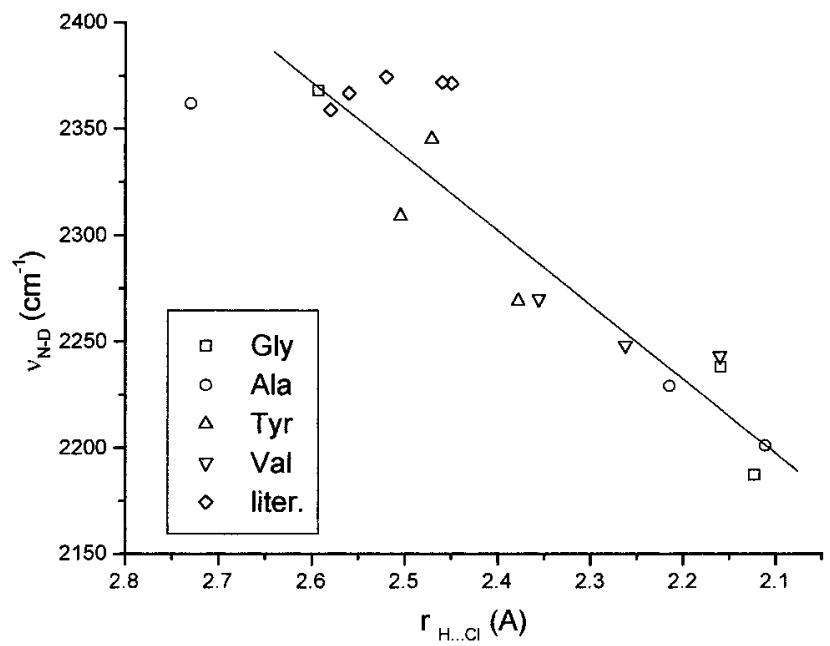

Figure 5. The projection of Figure 3 on the plane of frequency with hydrogen bond length. The data show a linear relationship with $R=$ 0.98 . Some of the data scatter is due to bifurcated hydrogen bonds. The standard deviation is $26.9 \mathrm{~cm}^{-1}$.

The bands of a given conformation in the tyrosine salt have similar widths: the bands at 2269, 2276, and $2334 \mathrm{~cm}^{-1}$ are about $7.2 \mathrm{~cm}^{-1}$ wide (fwhm), while the bands at 2281, 2287, and $2341 \mathrm{~cm}^{-1}$ are about $5.4 \mathrm{~cm}^{-1}$ wide. The band of the other $\mathrm{N}-\mathrm{D}$ conformation at $2309 \mathrm{~cm}^{-1}$ is $6.3 \mathrm{~cm}^{-1}$ wide. The widths $\left(7.2,6.3,5.4 \mathrm{~cm}^{-1}\right)$ are related to the main $\mathrm{N}-\mathrm{D}$ stretching frequencies $\left(2269,2309,2345 \mathrm{~cm}^{-1}\right)$ with the stronger hydrogen bonds (lower frequencies) having the widest bands. This is a well-established trend. ${ }^{11,13}$ We cannot establish this trend for our valine data, probably because the stretching bands are complicated by vibrational interactions and overlaps.

Hole-Burning Efficiency. To compare the hole-burning efficiency of different $\mathrm{N}-\mathrm{D}$ bands in different amino acid salts, we normalize the hole depth to an irradiation of $30 \mathrm{~min}$ and relative laser power of $4.1 \mathrm{~mW}$. This infrared laser power was measured in the middle of the laser optical path, and the irradiance at the sample was about $100 \mathrm{~mW} / \mathrm{cm}^{2}$. The hole depth is proportional to the absorbance of the band, and so we tabulate $\triangle A / A$, the relative hole-burning efficiency. We checked that the hole-burning efficiency is indeed linear with respect to the laser power at low power and in the short irradiation time limit. ${ }^{14}$ The laser powers we used in the amino acid experiments all fall in this low power range.

Hole-burning efficiencies for $\mathrm{N}-\mathrm{D}$ stretching bands for four amino acid salts are summarized in Table 6, arranged in order from the easiest to the most difficult one to burn. The efficiency for each salt varies with the spectral position of the laser. A measure of the overall ease of burning can be obtained by comparing the hole-burning difference spectra after either irradiation by the glower source or the laser. The depth of the holes is markedly different from salt to salt: the spectra vary with a maximum hole of about 0.02 AU for glycine hydrochloride for glower irradiation to about $0.0018 \mathrm{AU}$ for the alanine salt with laser irradiation. Qualitatively the glycine and tyrosine are about 3 times easier to burn than the valine and alanine.

The hole-burning process depends on the coupling between the stretching motion and the $\mathrm{NH}_{2} \mathrm{D}^{+}$libration. The persistence of the hole or antihole on our time scale also requires a librational barrier within a certain range: too high and the stretching photon will not provide enough energy to overcome it, too low and the amino group reequilibrates too rapidly. ${ }^{2}$ Our previous experiments on ammonium compounds suggested that the initial hole-burning process is relatively independent of the 
TABLE 6: Hole Burning Efficiency in Amino Acid Hydrochloride Salts

\begin{tabular}{|c|c|c|c|}
\hline $\begin{array}{c}v_{\mathrm{N}-\mathrm{D}} \\
\left(\mathrm{cm}^{-1}\right)\end{array}$ & $\begin{array}{c}\Delta \mathrm{A} / \mathrm{A} \\
(\%)^{a}\end{array}$ & $\begin{array}{c}\text { relative IR } \\
\text { power }(\mathrm{mW})\end{array}$ & $\begin{array}{l}\text { normalized } \\
\Delta \mathrm{A} / \mathrm{A}(\%)^{b}\end{array}$ \\
\hline \multicolumn{4}{|c|}{ Glycine } \\
\hline 2368 & & & $c$ \\
\hline 2238 & 5.03 & 20.5 & 1.01 \\
\hline 2187 & 0.96 & 16.4 & 0.24 \\
\hline \multicolumn{4}{|c|}{ Tyrosine } \\
\hline 2345 & 0.18 & 0.8 & 0.90 \\
\hline 2309 & 0.05 & 1.6 & 0.13 \\
\hline 2269 & 0.24 & 4.1 & 0.24 \\
\hline \multicolumn{4}{|c|}{ Valine } \\
\hline 2270 & 0.62 & 7.4 & 0.34 \\
\hline 2248 & 1.17 & 11.5 & 0.42 \\
\hline 2243 & 0.54 & 11.5 & 0.19 \\
\hline \multicolumn{4}{|c|}{ Alanine } \\
\hline 2362 & & & $c$ \\
\hline 2229 & 1.04 & 12.3 & 0.35 \\
\hline 2201 & 0.21 & 16.4 & 0.05 \\
\hline
\end{tabular}

${ }^{a}$ Observed hole burning efficiency for $30 \mathrm{~min}$ laser irradiation. ${ }^{b}$ Based on $4.1 \mathrm{~mW}$ laser power and assuming the hole burning efficiency is linear at low laser power. The laser power was measured in the optical path. ${ }^{c}$ The laser power here was too weak to produce an observable hole.

hydrogen-bond strength and thus the barrier. ${ }^{13}$ The barriers have been estimated by neutron diffraction for the tyrosine and valine hydrochlorides as 5.0 and $6.4 \mathrm{kcal} / \mathrm{mol}(21$ and $27 \mathrm{~kJ} / \mathrm{mol})$, respectively. 8,9 These relatively high barriers account for the observed stability of the holes over time on the order of 1 day at $7-10 \mathrm{~K}$.

\section{Glycylglycine Hydrochloride}

We now explore the possibility of using amino groups as probes to study intermolecular interactions in peptide salts. We start with glycylglycine hydrochloride, the simplest peptide salt, in the expectation that it will behave like the amino acid salts. The Gly-Gly-HCl crystallizes from water solution as the monohydrate. ${ }^{15,16}$ The crystal is of $P 2_{1} / c$ (No. 14) symmetry with $Z=4$, and all atoms are in general positions. In the deuterium stretching region, we expect three amino $\mathrm{N}-\mathrm{D}$ bands, one peptide $\mathrm{N}-\mathrm{D}$ band, and three $\mathrm{O}-\mathrm{D}$ bands, one from the carboxyl group and two from the water.

The absorption spectra of the hydrogenated and 5\% deuterated sample are shown in the bottom panel of Figure 6. Compared with simple amino acid salts discussed above, most of the deuterium-related bands (the difference between the hydrogenated and deuterated spectra) lie in the higher frequency region from 2270 up to $2450 \mathrm{~cm}^{-1}$, implying weaker hydrogen bonds.

Broadband irradiation produces holes at 2322 and $2385 \mathrm{~cm}^{-1}$, with antiholes at 2287 and $2380 \mathrm{~cm}^{-1}$. There are also some small spectral changes at about $2442 \mathrm{~cm}^{-1}$. Because the $\mathrm{N}-\mathrm{D}$ bands are at high frequencies, where the output of our differencefrequency laser is low, we employed our diode laser to holeburn the compound. The results for glycylglycine hydrochloride at $20 \mathrm{~K}$ with 1-h irradiation at each laser frequency are shown in Figure 6.

Laser irradiations at 2380 and $2385 \mathrm{~cm}^{-1}$ show different holeburning patterns, separating the broad peak in the absorption spectrum into two components. This is consistent with the broadband result, with a hole at $2385 \mathrm{~cm}^{-1}$ but an antihole at $2380 \mathrm{~cm}^{-1}$. Thus, 2380 and $2385 \mathrm{~cm}^{-1}$ belong to two of the possible $\mathrm{N}-\mathrm{D}$ positions of the $\mathrm{NH}_{2} \mathrm{D}^{+}$. The $2322 \mathrm{~cm}^{-1}$ irradiation yields a pattern similar to the $2385 \mathrm{~cm}^{-1}$ one, so these two bands belong to the same conformation. Irradiation

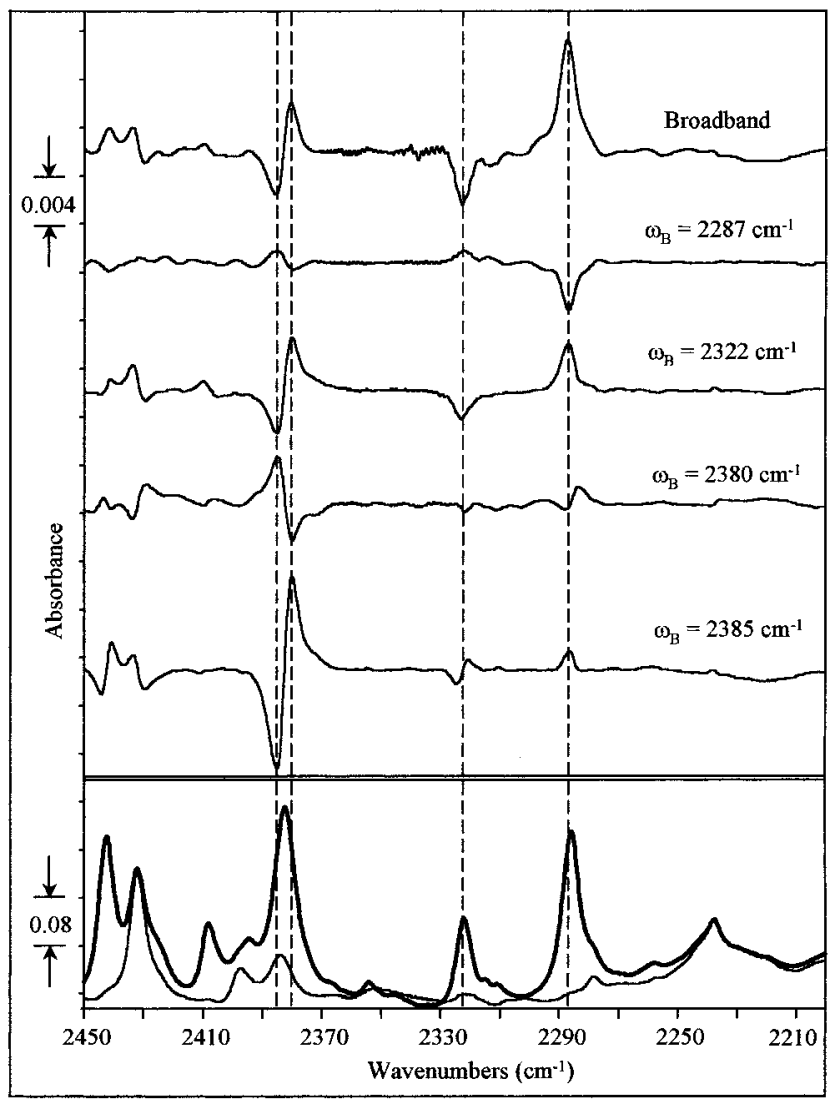

Figure 6. Infrared hole burning spectra of glycylglycine hydrochloride. Similar to Figure 1 . The sample with about $5 \%$ deuterium was irradiated by diode lasers for an hour. The dashed vertical lines are at 2287, 2322, 2380 , and $2385 \mathrm{~cm}^{-1}$.

TABLE 7: Hydrogen-Bonding Geometry and Deuterium Stretching Frequencies for Glycylglycine Hydrochloride Monohydrate

\begin{tabular}{lcccc}
\hline \multicolumn{1}{c}{$\mathrm{A}-\mathrm{H} \cdots \mathrm{B}$} & $\mathrm{A} \cdots \mathrm{B}^{b}(\AA)$ & $\mathrm{H} \cdots \mathrm{B}^{b}(\AA)$ & $\begin{array}{c}\angle \mathrm{A}-\mathrm{H} \cdots \mathrm{B}^{b} \\
(\mathrm{deg})\end{array}$ & $\begin{array}{c}\mathrm{A}-\mathrm{D} \\
\text { stretch }^{c} \\
\left(\mathrm{~cm}^{-1}\right)\end{array}$ \\
\hline $\mathrm{N}_{1-}-\mathrm{H}_{1} \cdots \mathrm{Cl}^{-}$ & $3.195(2)$ & $2.256(7)$ & $151.4(5)$ & 2385 \\
$\mathrm{~N}_{1}-\mathrm{H}_{1} \cdots \mathrm{Cl}^{\prime \prime}-$ & $3.184(2)$ & $2.268(6)$ & $147.4(5)$ & 2380 \\
$\mathrm{~N}_{1}-\mathrm{H}_{3} \cdots \mathrm{O}_{4}$ & $3.025(4){ }^{e}$ & $2.070(6)$ & $154.8(5)$ & 2287 \\
$\mathrm{~N}_{2}-\mathrm{H}_{6} \cdots \mathrm{Cl}^{-d}$ & $3.296(2)$ & $2.295(6)$ & $162.4(5)$ & 2410 \\
$\mathrm{O}_{3}-\mathrm{H}_{9} \cdots \mathrm{O}_{4}^{\prime \prime \prime}{ }_{e}$ & $2.644(5)$ & $1.658(6)$ & $166.8(5)$ & 2081 \\
$\mathrm{O}_{4-} \mathrm{H}_{10} \cdots \mathrm{O}_{1}{ }^{\mathrm{IV} e}$ & $2.728(4)$ & $1.764(6)$ & $170.7(6)$ & 2089 \\
$\mathrm{O}_{4}-\mathrm{H}_{11} \cdots \mathrm{Cl}^{\prime}{ }^{\prime}$ & $3.086(4)$ & $2.168(6)$ & $161.1(5)$ & 2257
\end{tabular}

${ }^{a}$ Neutron diffraction data. ${ }^{b}$ The numbers in parentheses are the errors in the last digit quoted taken from the X-ray reports. ${ }^{c}$ This work. ${ }^{d}$ Peptide bond. ${ }^{e} \mathrm{H}_{9}$ is the carboxyl hydrogen, $\mathrm{H}_{10}$ and $\mathrm{H}_{11}$ are the water hydrogens, $\mathrm{O}_{3}$ is the carboxyl oxygen, and $\mathrm{O}_{4}$ is the water oxygen.

at 2385,2380 , or $2322 \mathrm{~cm}^{-1}$ results in an antihole at $2287 \mathrm{~cm}^{-1}$. This assigns the $2287 \mathrm{~cm}^{-1}$ band to the third N-D conformation. The N-D stretch of the peptide bond is not expected to change on irradiation. Irradiation at $2410 \mathrm{~cm}^{-1}$ does not produce any hole-burning pattern, so we assign the deuterium-related band at $2410 \mathrm{~cm}^{-1}$ to the peptide bond. The small feature at $2442 \mathrm{~cm}^{-1}$ changes in the pattern of the band at $2380 \mathrm{~cm}^{-1}$ and belongs to the same conformation. There are a number of other features due to deuterium that do not change on irradiation; these include bands at 2257, 2394, and $2423 \mathrm{~cm}^{-1}$ (both shoulders) and sizable bands at 2081 and $2089 \mathrm{~cm}^{-1}$. A summary of the bands and a possible assignment are given in Table 7. The assignments of the bands that change on hole burning are definite, but those of the unburnable bands are an educated guess. We note that there are some other small features 
that represent Fermi resonance or combination bands of the conformations we have assigned.

The vibrational frequencies of "gas-phase" glycylglycine hydrochloride have been predicted by ab initio calculation. ${ }^{17,18}$ The calculations suggest that the $\mathrm{N}-\mathrm{H}$ stretching frequencies are 3265,3161 , and $3109 \mathrm{~cm}^{-1}$ for all-hydrogen molecules. ${ }^{18}$ With the isotopic substitution of a single deuterium, the frequencies are expected to shift by about the ratio of the reduced masses for $\mathrm{N}-\mathrm{H}$ and $\mathrm{N}-\mathrm{D}$, a factor of 0.7318 , to the lower frequencies 2389,2313 , and $2275 \mathrm{~cm}^{-1}$; the observed bands are at 2385,2380 , and $2287 \mathrm{~cm}^{-1}$. This is remarkable agreement, considering all the approximations in the comparison because the theoretical model has no water and has no intermolecular hydrogen bonding.

A recent study of Gly-Gly- $\mathrm{HCl}-\mathrm{H}_{2} \mathrm{O}$ by deuterium NMR concludes that the deuterium chemical shielding tensors, especially that for the carboxyl group deuterium, agrees well with the neutron diffraction crystal structure. ${ }^{19}$ Some additional NMR data on the $\mathrm{C}-\mathrm{C}$ distances are available, and this also agrees with the diffraction structure. ${ }^{20}$

Gly-Gly-Gly-HCl has one more peptide bond and so it should show three $\mathrm{N}-\mathrm{D}$ stretch bands from the amino group and two peptide $\mathrm{N}-\mathrm{D}$ stretches. We obtained crystals with some difficulty, but we were able to find one that gave an excellent broadband spectrum. This showed substantial holes and antiholes. Since we did not find a crystal structure, we did not pursue this further. We expect the usual three amino acid N-D stretch bands together with two additional peptide $\mathrm{N}-\mathrm{D}$ stretches. The number of $\mathrm{O}-\mathrm{D}$ bands would depend on the amount of water in the crystal.

\section{Summary}

Irradiating the $\mathrm{N}-\mathrm{D}$ stretch bands of a variety of amino acid salts and of two simple peptide salts changes the conformation of the $\mathrm{NH}_{2} \mathrm{D}^{+}$groups. The changes of conformation give rise to holes in the irradiated stretch band and any other band that arises from a vibration that contains a contribution from that stretch. The hole burning thus identifies complex overlapped stretch bands and often separates such bands into its constituent components. The stretching frequencies correlate well with the structural parameters of the hydrogen bond of the irradiated $\mathrm{N}-\mathrm{D}$ bond. The extension to peptide salts suggests that the holeburning technique is a general one, since the hole burning depends on the local properties of the $\mathrm{NH}_{2} \mathrm{D}^{+}$group.

Acknowledgment. We are pleased to acknowledge support from the National Science Foundation (CHE-98-15945).

\section{References and Notes} 5484.

(1) Yu, G.-S.; Li, H.-W.; Strauss, H. L. J. Phys. Chem. 1997, B101,

(2) Strauss, H. L. Acc. Chem. Res. 1997, 30, 37-42.

(3) Bellamy, L. J. The Infrared Spectra of Complex Molecules; Methuen: London, 1958.

(4) Creighton, T. E. Proteins: Structure and Molecular Principles; Freeman: New York, 1993.

(5) Tsuboi, M.; Onishi, T.; Nakagawa, I.; Shimanouchi, T.; Mizushima, S. Spectrochim. Acta 1958, 12, 253. 298.

(6) Li, H.-W.; Yu, G.-S.; Strauss, H. L. J. Phys. Chem. 1998, B102,

(7) Fei, S. and Strauss, H. L. J. Phys. Chem. 1996, 100, 3414.

(8) Frey, M. N.; Koetzle, T. F.; Lehmann, M. S.; Hamilton, W. C. J. Chem. Phys. 1973, 58, 2547.

(9) Koetzle, T. F.; Golic, L.; Lehmann, M. S.; Verbist, J. V.; Hamilton, W. C. J. Chem. Phys. 1974, 60, 4690.

(10) Jeffrey, G. A. An Introduction to Hydrogen Bonding; Oxford University Press: Oxford, 1997.

(11) Pimentel, G. C.; McClellan, A. L. The Hydrogen Bond; Freeman: San Francisco, CA, 1960.

(12) Knop, O.; Oxton, I. A.; Falk, M. Can. J. Chem. 1979, 57, 404

(13) Cho, H.-G.; Strauss, H. L. J. Chem. Phys. 1993, 93, 5661.

(14) Li, H.-W. Dissertation, University of California, Berkeley, 2000.

(15) Parthasarathy, R. Acta Crystallogr. 1969, B25, 509.

(16) Koetzle, T. F.; Hamilton, W. C.; Parathsarathy, R. Acta Crystallogr. 1971, B28, 2083

(17) Chakrabbort, D.; Yash, A.; Manogaran, S. J. Mol. Struct. 1994, $303,265$.

(18) Chakrabbort, D.; Manogaran, S. J. Phys. Chem. 1997, A101, 6964.

(19) Michal, C. A., Wehman, J. C., Jelinski, L. W. J. Magn. Reson 1996, $B 111,31$

(20) Costa, P. R., Sun, B. Q., Griffin, R. G. J. Am. Chem. Soc. 1997, 119,10821 